\title{
Lugano Classification Adult Lymphoma by AJCC v8 Stage
}

National Cancer Institute

\section{Source}

National Cancer Institute. Lugano Classification Adult Lymphoma by A/CC v8 Stage. NCI

Thesaurus. Code C141148.

A staging system for adult Hodgkin and adult non-Hodgkin lymphomas based on the Lugano classification criteria. This staging system does not apply to ocular adnexal lymphomas (are staged according to the classification for ocular adnexal lymphoma), pediatric lymphomas (are staged according to the classification for pediatric lymphoma), primary cutaneous lymphomas (are staged according to the classification for primary cutaneous lymphoma), and multiple myelomas (are staged according to the classification for plasma cell myeloma). (from AJCC 8th Ed.) 